\title{
Respuesta al comentario del Dr. Prada-Madrid
}

\section{Gustavo MANTRANA}

Estimado Dr. Prada, quiero enviarle primeramente un cálido y fraterno saludo; agradezco tan enriquecedor y positivo comentario sobre nuestro artículo y debo elogiar su extraordinaria capacidad de síntesis. Creo que actualmente son indiscutibles las múltiples ventajas que proporciona la aplicación de esta tecnología en diferentes áreas de la ciencia; las ciencias de la salud no escapan a esta afirmación, y por el contrario, son en las que más beneficios se han destacado en este corto plazo desde que esta tecnología se ha hecho accesible de forma casi global. Hemos sido testigos del crecimiento exponencial en la formulación de artículos científicos en esta materia asociada a las diferentes ramas de la Medicina y cada vez con más frecuencia los vemos en revistas de Cirugía Plástica. Los autores de este artículo entendemos que la impresión 3D representa una tecnología que vino para quedarse, y por ello, su estudio, análisis y aplicación en nuestra especialidad debe ser incentivado. En la medida que los avances tecnológicos permiten sumar y complementar los procesos diagnósticos y terapéuticos existentes, enriquecen de forma sustancial nuestra práctica profesional con un impacto directo que afecta positivamente a la calidad de atención de nuestros pacientes.
La principal barrera que encontramos en nuestros medios es la económica, y el acceso a la impresión 3D se vio durante algunos años relegado a unos cuantos laboratorios científicos asociados principalmente a instituciones universitarias o centros dedicados a la investigación científica; sin embargo, como toda nueva tecnología, con el paso de los años los costos disminuyen y su alcance se amplía. Actualmente el costo de creación de un laboratorio funcional de impresión 3D en un centro hospitalario ya sea público o privado, en el marco de la enseñanza académica o no, es completamente asequible y bien justificado, sin embargo es en este último en el que más ventajas le vemos.

Por último, no puedo dejar de mencionar el futuro prometedor que se vislumbra en pocos años en cuanto a las aplicaciones de esta tecnología. El desarrollo de nuevos materiales que se asemejan cada vez más a los tejidos biológicos hace pensar en las posibles aplicaciones, pero es sin duda la bioimpresión la que representa un verdadero salto, rompiendo las barreras de la imaginación en cuanto a lo que se puede llegar a lograr y su impacto en la humanidad. 